\title{
Decisão de Carreira entre Estudantes em Fim de Curso Universitário
}

\author{
Marco Antônio Pereira Teixeira \\ Universidade Federal de Santa Maria \\ William B. Gomes ${ }^{1}$ \\ Universidade Federal do Rio Grande do Sul
}

\begin{abstract}
RESUMO - O estudo avaliou a contribuição de clareza de autoconceito, auto-eficácia profissional, comportamento exploratório, participação em atividades acadêmicas de formação, situação do mercado de trabalho e percepção pessoal de oportunidades profissionais na predição da decisão de carreira, entre estudantes em fim de curso universitário. Participaram 252 estudantes com idades entre 20 e 30 anos, que responderam um instrumento de auto-relato desenvolvido para a pesquisa. Uma análise de regressão mostrou que as variáveis percepção de oportunidades, auto-eficácia profissional e clareza de autoconceito foram as que mais contribuíram para a predição da decisão de carreira. Neste sentido, interpretou-se que a formação universitária contemple com mais ênfase o aspecto da prática profissional, como forma de promover o desenvolvimento do autoconceito e da auto-eficácia. Sugere-se que a universidade ofereça atividades relacionadas ao desenvolvimento de metas profissionais para que os estudantes lidem de modo efetivo com a transição para o mercado de trabalho.
\end{abstract}

Palavras-chave: decisão de carreira; desenvolvimento vocacional; universitários.

\section{Career Decision among Senior College Students}

\begin{abstract}
This study evaluated the contribution of self-concept clarity, professional self-efficacy, exploratory behavior, participation in academic activities, labor market situation, perception of barriers to entrance in the labor market, perceived support to career plan, and perceived level of work opportunities in the predicting career decision-making among senior college students. Subjects (252 students between 20 and 30 years old) completed a self-report instrument specially developed for this research. Regression analysis showed that perceived level of work opportunities, professional self-efficacy, and self-concept clarity were the variables that contributed most to the prediction of career decision-making. The study highlights the need of an emphasis on practical aspects of professional education in university training, as a way to assist students in developing self-concept and self-efficacy. It also suggests that the university should teach students to cope effectively with their transition to the labor market, and to develop the abilities to set professional goals and utilize career development strategies.
\end{abstract}

Key words: career decision; vocational development; university students.

Os estudantes universitários concluem seus cursos com diferentes atitudes e expectativas frente ao futuro profissional. Embora exista um certo otimismo quanto ao futuro ao final da graduação (Graham \& McKenzie, 1995), a falta de conhecimentos sobre os desafios nas especificidades das respectivas áreas de atuação parece ser uma situação bastante comum (Gondim, 2002; Perrone \& Vickers, 2003). Apesar disso, alguns se sentem confiantes em suas capacidades, estabelecem planos profissionais e iniciam um percurso na tentativa de realizá-los. Outros, contudo, chegam ao final de seus estudos sem saber muito bem o que fazer. Com efeito, aqueles que se sentem mais definidos em relação à profissão escolhida têm maiores chances de realizar seus projetos e de alcançar satisfação profissional. Desta forma, metas profissionais razoavelmente claras contribuem para orientar ações e monitorar progressos na carreira, facilitando a identificação de obstáculos e a correção de rumos (Greenhaus, Callanan \& Kaplan, 1994). Pergunta-se então: quais fatores contribuem para a definição de metas profissionais, aqui denominadas de decisão de carreira?

1 Endereço: Rua Gen. Couto de Magalhães, 1155/601, Santa Maria, Rio Grande do Sul, Brasil 90540-131.E-mail: gomesw@ufrgs.br
Em geral, a decisão de carreira é definida como a competência que um indivíduo possui de escolher e comprometer-se com uma dada direção educacional ou vocacional (Osipow, Carney \& Barak, 1976). Um outro sentido dado a decisão de carreira é o de identidade vocacional (Spokane, 1996), ou seja, a clareza que o indivíduo tem dos seus objetivos, interesses e talentos profissionais. Neste estudo, a decisão de carreira, também chamada de decisão em relação ao projeto profissional, é entendida como a capacidade que um indivíduo tem de identificar seus interesses dentro da profissão, estabelecer objetivos profissionais que espera alcançar e traçar uma estratégia de ação coerente com esses objetivos. Ela é um indicador da capacidade de antecipar o desenvolvimento da carreira e de planejar as ações necessárias para a consecução das metas desejadas. A decisão de carreira não se limita à escolha de um campo específico de atuação dentro da profissão, mas implica também na preparação e na determinação do indivíduo para implementar seus projetos.

Uma vez que a decisão de carreira está relacionada à elaboração de um plano profissional em função das expectativas futuras, a situação do mercado de trabalho surge como uma variável importante que pode dificultar esse processo nos casos de profissões que apresentam poucas oportunidades 
de trabalho. Ou seja, a falta de alternativas profissionais poderia provocar ambivalência nos formandos sobre qual caminho seguir dentro da profissão, dada a incerteza quanto à possibilidade de realização dos projetos profissionais sinalizada pelo mercado. Essa hipótese foi investigada por Neiva (1996) que observou resultados contrários aos esperados: estudantes vinculados a profissões com mercado de trabalho fraco mostraram-se mais decididos quanto aos seus projetos pós-universitários do que os vinculados a profissões com mercado mais promissor. No entanto, os resultados de Neiva estavam baseados em um único item do questionário que perguntava se o sujeito já havia definido o que fazer após terminar o curso universitário, com opções de resposta "sim", "não" e "em dúvida". Note-se que o item não avaliou o nível de elaboração e planejamento da decisão tomada, atributos estes que caracterizariam uma decisão teoricamente mais madura.

Sabe-se que a existência de oportunidades no mercado de trabalho favorece o desenvolvimento de projetos e de expectativas profissionais em formandos universitários. Contudo, pouco se sabe acerca de outros fatores que possam estar associados à decisão de carreira nesse tipo de população. No único estudo brasileiro localizado que abordou especificamente essa questão (Neiva, 1995), observou-se que, em um grupo com perspectivas de trabalho mais promissoras, os sujeitos mais decididos eram menos ansiosos e estimavam mais ofertas de emprego do que os menos decididos. Por outro lado, em um grupo com oportunidades de trabalho reduzidas, a decisão mostrou-se associada positivamente com a motivação em relação à profissão e negativamente com a ansiedade. Tais achados sugerem que a ansiedade tem um papel importante na decisão de carreira, especialmente entre os estudantes que estão ingressando em profissões com mercados de trabalho menos favoráveis.

Certamente, há outras variáveis que, em conjunto com a situação do mercado, influenciam a decisão de carreira ao final de curso universitário. São variáveis presentes em várias circunstâncias associadas à escolha e à manutenção profissional tais como: clareza de autoconceito (Super, Savickas \& Super, 1996), expectativas de auto-eficácia (Bandura, 2001), comportamento exploratório (Jordaan, 1963) e percepção de barreiras e apoios (Swanson \& Tokar, 1991). A essa lista de variáveis pode ser acrescentada a percepção das possibilidades pessoais.

Clareza de autoconceito refere-se ao quanto as crenças relativas a si mesmo (ou seja, os atributos pessoais percebidos) são claramente definidas, consistentes e estáveis no tempo (Campbell \& cols., 1996). Uma imagem clara de si mesmo é fundamental para a realização de escolhas e de planos congruentes com os próprios interesses (Greenhaus \& cols., 1994). Na verdade, o desenvolvimento vocacional é este processo de traduzir e implementar o autoconceito em termos profissionais (Super \& cols., 1996). Portanto, espera-se encontrar uma associação entre a clareza de autoconceito e o nível de decisão de carreira ao final do curso universitário.

Expectativas de auto-eficácia (Betz, 1994; Gianakos, 1999; Lent, Brown \& Hackett, 1996; Pinquart, Juang \& Silbereisen, 2003) são crenças que um indivíduo tem a respeito da sua capacidade de executar com sucesso um dado comportamento. Uma percepção de baixa eficácia pode levar o indivíduo a evitar a execução do tal comportamento devido às suas expectativas negativas de desempenho (Bandura, 2001). Sendo assim, as crenças de auto-eficácia relativas à profissão devem ser um fator associado à decisão de carreira, pois a elaboração de um projeto de carreira exige que o indivíduo perceba-se capaz de desempenhar-se bem nas atividades profissionais. Isto é, supõe-se que um senso de competência e segurança para o exercício profissional ao fim do curso universitário seja um correlato da decisão de carreira nesse período.

Os comportamentos exploratórios vocacionais são caracterizados como se tratando de ações presentes na preparação pessoal para a escolha de uma carreira. O objetivo destes comportamentos é obter informações sobre o sujeito da ação e sobre os contextos de interesse, a fim de orientar as ações futuras (Blustein, 1997; Jordaan, 1963). Atividades de exploração intencionais, isto é, comportamentos exploratórios iniciados pelo próprio sujeito visando preparar-se para o ingresso no mercado de trabalho parecem ser elementos que contribuem para a elaboração de projetos profissionais de jovens universitários formandos. Esses comportamentos podem ser descritos como iniciativas para buscar informações sobre locais de trabalho, estabelecer contatos com profissionais da área, e buscar estágios e cursos que possam facilitar a obtenção de emprego ou trabalho. Assim, espera-se que a decisão de carreira esteja associada a níveis mais elevados de comportamentos exploratórios vocacionais. Além disso, a participação em atividades acadêmicas de formação, como monitorias e bolsas de pesquisa, também também pode ser considerada como comportamento exploratório, pois permite ao estudante tomar um contato mais intenso com a profissão. No entanto, como são atividades exploratórias mais específicas, são consideradas neste estudo separadamente das demais atividades de exploração.

A percepção de barreiras e de apoios ao projeto profissional do graduando parece ser outro aspecto importante na decisão de carreira (Lent, Brown \& Hackett, 2000; Swanson \& Tokar, 1991). Se a percepção de barreiras realmente afeta o desenvolvimento desses projetos, então a decisão de carreira deve estar inversamente relacionada ao nível de dificuldades percebidas pelos indivíduos. Além disso, a elaboração de projetos profissionais ao final de um curso universitário é uma tarefa potencialmente ansiogênica, uma vez que não existem garantias quanto à realização desses projetos. Dessa forma, indivíduos que se sentem apoiados em relação aos seus planos profissionais, no sentido de terem com quem contar no seu percurso de estabelecimento na profissão, devem apresentar níveis de decisão de carreira mais elevados do que aqueles que não contam com tal tipo de apoio. De fato, a literatura em desenvolvimento vocacional tem mostrado que a percepção de apoio recebido e a aproximação afetiva, tanto de pais quanto de amigos, está associada a níveis mais altos de decisão de carreira, tanto entre adolescentes quanto entre estudantes universitários (Blustein, Prezioso \& Schultheiss, 1995; Feldman, 2003; Kräcke, 1997; Tokar, Withrow, Hall \& Moradi, 2003).

Por fim, a decisão de carreira também deve estar associada à percepção de cada indivíduo acerca das suas possibilidades pessoais de conseguir um trabalho satisfatório dentro da sua 
profissão. A expectativa de boas oportunidades de trabalho deve atuar como um elemento facilitador do processo de decisão, pois o indivíduo não necessitaria ajustar seu projeto às demandas do mercado, podendo optar por um caminho profissional voltado aos interesses pessoais.

O presente estudo teve por objetivo investigar variáveis possivelmente associadas à decisão de carreira entre estudantes em fim de curso universitário. Desta forma, investigaram-se as possíveis associações entre o nível de decisão de carreira ao fim de curso universitário e as variáveis: clareza de autoconceito, auto-eficácia profissional, comportamento exploratório, participação em atividades acadêmicas de formação (pesquisa e monitoria), situação do mercado de trabalho, percepção de dificuldades para ingresso no mercado de trabalho, percepção de apoio ao projeto profissional e percepção pessoal de oportunidades profissionais. Uma vez que a idade pode influenciar o desenvolvimento vocacional, em virtude das demandas do próprio ciclo vital e também por conta da maturidade que a experiência de vida proporciona, nesta pesquisa restringiu-se a faixa etária estudada ao limite de 30 anos, priorizando assim o estudo do fenômeno entre adultos jovens. De modo complementar, procurou-se também verificar, entre as variáveis estudadas, as melhores preditoras da auto-eficácia profissional percebida e da percepção de oportunidades profissionais.

\section{Método}

\section{Participantes}

Compuseram a amostra final deste estudo 252 estudantes (60,7\% mulheres) de 24 cursos de uma universidade pública, com idades variando de 20 a 30 anos, com média de 23,9. A seleção dos cursos foi feita por critério de conveniência e disponibilidade de acesso aos formandos, mas buscando abranger o maior número possível de cursos. A opção por uma amostra de conveniência deu-se em virtude da dificuldade de se conseguir contatar os possíveis participantes de um modo aleatório. Ressalte-se que amostras de conveniência são extremamente importantes para a pesquisa psicológica. $\mathrm{Na}$ verdade, o uso de amostras aleatórias é muito raro em psicologia (Stanovich, 2004), fato esse há muito discutido na literatura, mesmo em se tratando de estudos populacionais (Mook, 1983). Os seguintes cursos foram contemplados nesta pesquisa (o número de casos por curso é indicado entre parênteses): Publicidade e Propaganda (4), Educação Física (17), Ciências Contábeis (4), Biblioteconomia (9), Farmácia (38), Pedagogia (8), Enfermagem (8), Medicina (17), Letras (11), Engenharia Mecânica (15), Economia (6), Geografia (7), Relações Públicas (4), Engenharia de Alimentos (5), Química (6), Engenharia Civil (11), Arquitetura (8), Veterinária (3), Odontologia (44), História (4), Psicologia (11), Matemática (3), Jornalismo (4) e Engenharia Química (5).

\section{Instrumento}

As variáveis de interesse foram avaliadas através de um questionário especialmente desenvolvido como parte de um estudo mais amplo em desenvolvimento vocacional e de carreira. Com base nas definições teóricas apresentadas na introdução, foram construídas escalas de auto-relato para mensurar as variáveis relevantes. Em geral, o gradiente de resposta foi um sistema Likert de cinco pontos, indicando diferentes graus de concordância com as afirmações. O conjunto de itens usado para avaliar decisão de carreira, clareza de autoconceito, auto-eficácia profissional, percepção de apoio ao projeto profissional e percepção de oportunidades profissionais foi submetido a análise de componentes principais a fim de que se avaliasse a validade fatorial dos construtos e se pudesse eliminar itens que não funcionassem conforme o desejado. Os resultados desta análise mostraram a distinção empírica dos construtos. Já os itens relativos a comportamento exploratório vocacional foram analisados à parte, tendo-se criado duas subescalas, conforme explicitado adiante. A seguir são descritas as variáveis envolvidas no estudo e o modo como foram avaliadas.

Decisão de carreira (decisão em relação ao projeto profissional): foi avaliada por um conjunto de 10 itens (alpha de Cronbach igual a 0,90). Exemplos de itens: "Eu sei o que eu preciso fazer para realizar as minhas metas profissionais" e "Eu tenho planos profissionais já bem estabelecidos".

Clareza de autoconceito: foi avaliada por um conjunto de 10 itens traduzidos de Campbell e cols. (1996). O índice de consistência interna (alpha de Cronbach) observado nesta amostra foi de 0,85. Exemplos de itens (sentido reverso): "Minhas crenças sobre mim mesmo freqüentemente são conflitantes" e "Um dia eu tenho uma opinião sobre mim mesmo e outro dia já tenho outra opinião".

Auto-eficácia profissional: foi avaliada por um conjunto de sete itens (alpha de Cronbach igual a 0,82). Exemplos de itens: "Eu tenho as habilidades necessárias para exercer a minha profissão eficazmente" e "Eu me sinto seguro para exercer a minha profissão".

Percepção de apoio ao projeto profissional: foi avaliada por um conjunto de cinco itens (alpha de Cronbach igual a 0,69). Exemplos de itens: "Meus planos profissionais têm o apoio de pessoas que são importantes para mim" e "Pessoas que são significativas para mim têm me estimulado a investir em minha profissão".

Percepção de oportunidades profissionais: foi avaliada por um conjunto de cinco itens (alpha de Cronbach igual a 0,78). Exemplos de itens: "Penso que será fácil obter um trabalho remunerado satisfatório na minha profissão" e "Acho que não será difícil minha inserção no mercado de trabalho".

Comportamento exploratório vocacional: foi avaliado por um conjunto de seis itens adaptados do Questionário de Exploração de Carreira de Stumpf, Colarelli e Hartman (1983), já utilizados no Brasil por Frischenbrüder (1999), acrescido de mais dois itens referentes à realização de cursos e estágios extra-curriculares. Uma análise de componentes principais destes itens sugeriu a existência de duas dimensões subjacentes ao comportamento exploratório vocacional: exploração de informação (alpha de Cronbach de 0,69) e exploração de prática (alpha de Cronbach de 0,62). Exemplos de itens da subescala de exploração de prática: "Experimentei diferentes atividades profissionais" e "Busquei oportunidades para praticar as habilidades referentes à minha profissão". Exemplos de itens da subescala de exploração de informação: "Obtive informações sobre tipos de trabalho específicos que 
eu gostaria de ter" e "Busquei informações sobre o mercado de trabalho e oportunidades de emprego em geral na minha profissão".

Participação em atividades acadêmicas de formação (bolsa e monitoria): foi avaliada através de dois itens referentes ao tempo de participação em bolsas de pesquisa ou monitoria de disciplinas durante o curso. De acordo com a distribuição das respostas nestes dois itens, os sujeitos tiveram sua participação classificada dicotomicamente em "participou da atividade por mais de um ano" e "teve participação na atividade por no máximo um ano (ou não teve)". Note-se que são duas variáveis distintas: participação em bolsa de pesquisa e participação em monitoria.

Percepção de barreiras: o nível de dificuldades percebidas para ingressar no mercado de trabalho foi avaliado através do somatório de pontos atribuídos em um conjunto de 11 itens que trata das dificuldades percebidas para ingresso no mercado de trabalho (exemplos: "falta de conhecimentos sobre alternativas de atuação profissional na minha área", "mercado de trabalho restrito", "falta de clareza sobre quais são meus interesses específicos na profissão", "falta de contato com pessoas da área que possam ajudar na inserção no mercado de trabalho"). Cada item foi avaliado numa escala de três pontos $-0,1$ e $2-$ de acordo com o grau percebido em que a possível barreira descrita no item poderia dificultar o ingresso no mercado de trabalho. Uma vez que não havia expectativa teórica de que estas barreiras se relacionassem a um traço latente comum (que seria a razão da variabilidade observada nos itens), elas foram tomadas apenas como indicadores do nível geral de barreiras percebidas, motivo pelo qual não foi calculada consistência interna para este conjunto de itens.

Avaliação da situação do mercado de trabalho na profissão: foi avaliada através das representações que os próprios formandos tinham a respeito do mercado de suas respectivas profissões, indicando suas impressões em uma escala categórica ordinal (item único) com seis opções: "muito bom", "bom", "razoável mas tendendo a bom", "razoável mas tendendo a ruim", "ruim" e "muito ruim". Posteriormente, foi realizada uma média das avaliações para cada um dos cursos e eles foram ordenados conforme o nível de oportunidades percebidas pelos estudantes (para tanto a escala ordinal foi tratada como intervalar). A lista ordenada foi então dividida ao meio em dois grupos: um com cursos de mercado de trabalho considerado mais favorável e outro com cursos de mercado considerado menos favorável. Cada participante, então, pôde ser classificado como pertencendo a um ou outro desses dois grupos (variável dicotômica).

Desempenho acadêmico: avaliado através de um item único de auto-relato, com cinco opções de resposta: entre 50 e $59 \%$, entre 60 e $69 \%$, entre 70 e $79 \%$, entre 80 e $89 \%$ e entre 90 e $100 \%$.

\section{Procedimentos}

Os contatos foram realizados predominantemente em reuniões e ensaios de formatura, quando os questionários foram entregues em envelopes selados e endereçados para serem enviados de volta pelo correio após serem respondidos. Em alguns cursos foi possível aplicar os questionários em sala de aula. Em todos os casos, os questionários foram aplicados faltando menos de um mês para o encerramento do semestre. De um total de 608 questionários entregues no envelope ou aplicados em aula, 296 foram obtidos de volta $(47,9 \%)$. Vinte e seis participantes que responderam o questionário foram excluídos das análises por terem idade superior ao estabelecido (máximo de 30 anos), quatro por pertencerem a algum curso que foi representado por menos de três indivíduos no estudo, e outros 14 foram excluídos posteriormente por apresentarem escores extremos (maiores do que 3 desvios-padrão) em alguma das variáveis de interesse central da pesquisa. Em todas as situações, explicou-se os objetivos da pesquisa e se solicitou aos interessados em participar (inclusive no caso de receberem os questionários para serem depois retornados por correio) que assinassem um termo de consentimento informado, no qual se explicitava o caráter voluntário da participação na pesquisa e se garantia a confidencialidade dos dados.

\section{Análise dos dados}

A análise dos dados consistiu na realização de três análises de regressão múltipla, tendo como variáveis dependentes a decisão de carreira, a auto-eficácia profissional e a percepção de oportunidades profissionais. Este procedimento de análise foi escolhido para examinar, simultaneamente, as contribuições específicas de cada preditor na explicação das variáveis dependentes (Tabachnik \& Fidell, 2001).

No caso da decisão de carreira, foram variáveis preditoras a clareza de autoconceito, a auto-eficácia profissional, o apoio percebido ao projeto profissional, a percepção de barreiras à execução do projeto, a exploração de informação, a exploração de prática, a percepção de oportunidades profissionais e as experiências de bolsa de pesquisa e de monitoria. Situação do mercado de trabalho e sexo foram incluídas como variáveis de controle a fim de que os possíveis efeitos das demais variáveis sobre a decisão que viessem a ser observados pudessem ser considerados independentes da situação do mercado de trabalho e do sexo.

Para a auto-eficácia profissional, foram tomadas como variáveis preditoras exploração de informação, exploração de prática, bolsa de pesquisa, bolsa de monitoria e desempenho acadêmico, uma vez que existe a hipótese teórica de que a experiência e o conhecimento contribuem para o desenvolvimento da auto-eficácia. Sexo foi incluído como variável de controle a fim de que os efeitos das demais variáveis sobre a auto-eficácia pudessem ser considerados independentes do sexo.

Por sua vez, a percepção de oportunidades profissionais teve como preditoras a auto-eficácia profissional (argumentando-se que só quem acredita nas suas potencialidades pode ter expectativas otimistas quanto à sua colocação no mercado de trabalho), o apoio percebido ao projeto profissional (uma vez que poder contar com a ajuda de outros pode facilitar o ingresso no mercado), a participação em monitorias/bolsas e a exploração de prática (pela qualificação que essas atividades supostamente propiciam) e a exploração de informação (pelo conhecimento a respeito do mercado que essa atividade proporciona). Novamente situação do mercado de trabalho e sexo foram incluídas como variáveis de controle a fim de que 
os possíveis efeitos das demais variáveis sobre a percepção de oportunidades que viessem a ser observados pudessem ser considerados independentes da situação do mercado de trabalho e do sexo.

\section{Resultados}

A Tabela 1 apresenta os resultados da análise de regressão para a variável decisão de carreira. O modelo mostrou-se significativo, com um $R^{2}$ (ajustado) $=0,53$, indicando que cerca de $53 \%$ da variação na decisão de carreira é explicada pelo conjunto das variáveis preditoras $[F(11,239)=26,34$; $p<0,001]$.

Observando-se os coeficientes de regressão padronizados (betas), nota-se que as variáveis percepção de oportunidades, auto-eficácia profissional e clareza de autoconceito foram as que mais contribuíram para a predição da decisão de carreira considerando-se o modelo proposto. Já a exploração de informação e o apoio percebido em relação ao projeto profissional mostraram-se menos relevantes para a predição da decisão, embora os coeficientes ainda tenham sido signi-

Tabela 1. Análise de regressão múltipla para a variável dependente decisão de carreira (resultados resumidos).

\begin{tabular}{lcc}
\hline Preditor & Beta & $\boldsymbol{p}$ \\
\hline Percepção de oportunidades & 0,24 & $<0,001$ \\
Auto-eficácia profissional & 0,23 & $<0,001$ \\
Clareza de autoconceito & 0,23 & $<0,001$ \\
Exploração de informação & 0,15 & 0,002 \\
Apoio percebido & 0,15 & 0,002 \\
Percepção de barreiras & $-0,11$ & 0,023 \\
Situação do mercado & 0,09 & 0,076 \\
Exploração de prática & $-0,06$ & 0,215 \\
Bolsa de pesquisa & 0,05 & 0,298 \\
Sexo & 0,04 & 0,404 \\
Monitoria & 0,01 & 0,801 \\
\hline Nota: Beta significa coeficiente de regressão padronizado
\end{tabular}

Tabela 2. Análise de regressão múltipla para a variável dependente autoeficácia profissional (resultados resumidos).

\begin{tabular}{lcc}
\hline Preditor & Beta & $\boldsymbol{p}$ \\
\hline Exploração de informação & 0,18 & 0,008 \\
Exploração de prática & 0,16 & 0,013 \\
Bolsa de pesquisa & 0,13 & 0,032 \\
Desempenho acadêmico & 0,10 & 0,128 \\
Monitoria & $-0,05$ & 0,407 \\
Sexo & 0,05 & 0,406 \\
\hline
\end{tabular}

Nota: Beta significa coeficiente de regressão padronizado ficativos $(p<0,05)$. Da mesma forma, uma alta percepção de barreiras mostrou-se negativa e significativamente associada à decisão. De maneira não esperada, nenhuma das variáveis relacionadas à formação prática (exploração de prática, bolsa e monitoria) contribuíram significativamente neste modelo.

É possível que as práticas não tenham se mostrado boas preditoras da decisão porque podem ter seu poder explicativo partilhado com outras variáveis presentes no modelo, especialmente a auto-eficácia. Em função disso, testou-se um modelo de regressão para auto-eficácia, conforme especificado anteriormente. $\mathrm{O}$ modelo de regressão proposto mostrouse significativo, com um $R^{2}$ (ajustado)=0,12, indicando que cerca de $12 \%$ da variação na auto-eficácia é explicada pelo conjunto das variáveis preditoras $[F(7,242)=5,65 ; p<0,001]$. A Tabela 2 apresenta os resultados dessa análise.

Os resultados indicam que as variáveis exploração de informação, exploração de prática e participação em bolsa de pesquisa contribuíram significativamente $(p<0,05)$ para a explicação do nível de auto-eficácia percebida. Isto sugere que estas variáveis são importantes para a promoção da autoeficácia, uma vez que elas estão relacionadas a experiências de aprendizagem que, supostamente, antecedem o desenvolvimento do senso de competência profissional. Deve-se observar, contudo, que este modelo explicou apenas $12 \%$ da variação em auto-eficácia, o que indica que outras variáveis não incluídas aqui também devem ser importantes para o desenvolvimento da auto-eficácia profissional.

Por fim, examinou-se a contribuição de algumas variáveis para a explicação da percepção de oportunidades profissionais, variável que expressa o otimismo dos formandos em relação ao seu ingresso e estabelecimento no mercado de trabalho. A Tabela 3 apresenta os resultados dessa análise. O modelo proposto mostrou-se significativo, com um $R^{2}$ (ajustado) $=0,32$, indicando que aproximadamente $32 \%$ da variação na percepção de oportunidades é explicado pelas variáveis aqui consideradas $[F(8,242)=15,99 ; p<0,001]$.

Os coeficientes de regressão padronizados nos indicam que a auto-eficácia profissional e a situação do mercado de trabalho são as variáveis que mais explicam a variável-critério, seguidas pelo apoio percebido ao projeto profissional. De modo contra-intuitivo, o tempo de bolsa de pesquisa

Tabela 3. Análise de regressão múltipla para a variável dependente percepção de oportunidades profissionais (resultados resumidos).

\begin{tabular}{lcc}
\hline \multicolumn{1}{c}{ Preditor } & Beta & $\boldsymbol{p}$ \\
\hline Auto-eficácia profissional & 0,36 & $<0,001$ \\
Situação do mercado & 0,31 & $<0,001$ \\
Apoio percebido & 0,15 & 0,006 \\
Bolsa de pesquisa & $-0,13$ & 0,019 \\
Exploração de prática & 0,08 & 0,161 \\
Monitoria & 0,04 & 0,502 \\
Exploração de informação & 0,03 & 0,575 \\
Sexo & 0,01 & 0,800 \\
\hline Nota: Beta significa coeficiente de regressão padronizado &
\end{tabular}

Nota: Beta significa coeficiente de regressão padronizado 
contribuiu negativamente para a predição da percepção pessoal de oportunidades profissionais, enquanto as demais variáveis não obtiveram coeficientes significativamente diferentes de zero.

\section{Discussão}

Os resultados da análise de regressão para a variável decisão de carreira confirmaram as expectativas teóricas. A percepção de oportunidades profissionais, a auto-eficácia profissional, a clareza de autoconceito, a exploração de informação, o apoio percebido em relação ao projeto profissional e uma baixa percepção de barreiras mostraram-se preditores da decisão de carreira. É interessante notar que a situação do mercado de trabalho, introduzida como variável-controle, não se mostrou um preditor significativo nesse modelo. Por outro lado, a percepção pessoal de oportunidades profissionais foi o preditor mais saliente. Tal resultado sugere que a decisão de carreira depende mais da forma como o indivíduo percebe o mercado de trabalho do que propriamente das suas condições objetivas, o que evidencia a importância do papel ativo que tem o indivíduo no processamento das influências que vêm do ambiente ao tomar decisões relativas à sua carreira (Albert \& Luzzo, 1999; Lent \& cols., 2000). Indivíduos que percebem o futuro profissional de uma maneira mais otimista possivelmente se sintam mais motivados a enfrentar eventuais dificuldades que possam encontrar pelo caminho, a começar pela dificuldade que é traçar metas profissionais diante da incerteza que toma conta do mercado de trabalho.

Os resultados indicaram também que um senso de competência profissional e clareza sobre si mesmo são fatores importantes na formação de planos profissionais, o que está de acordo com a teoria do desenvolvimento vocacional de Donald Super (Super \& cols, 1996) e com a teoria da autoeficácia de Albert Bandura (Bandura, 2001). Além disso, a exploração de informação mostrou ser um preditor da decisão de carreira, sugerindo que a busca por informações acerca da profissão de fato instrumentaliza o indivíduo para a elaboração de um plano profissional pós-formatura mais amadurecido (Super, 1983). Ainda, o apoio percebido em relação ao projeto profissional também contribuiu para a predição da decisão de carreira, o que ressalta a importância da presença de uma rede de apoio para os jovens formandos a fim de que o processo de decisão acerca do futuro profissional seja facilitado. Pode-se imaginar várias possibilidades através das quais familiares e amigos podem contribuir para uma maior decisão de carreira: estimulando os formandos a explorarem opções profissionais, servindo de interlocutores na formulação de planos para o futuro ou ainda simplesmente oferecendo apoio emocional que, sabe-se, é fator que facilita comportamentos exploratórios (Blustein, 1997; Blustein \& cols., 1995).

O fato de que atividades exploratórias de caráter prático não tenham sido identificadas como preditores significativos da decisão ensejou a realização de análises complementares, pois o envolvimento em atividades práticas é tido como um facilitador do processo de decisão na medida em que permite um maior autoconhecimento e desenvolvimento de competências profissionais (Blustein, 1997; Jordaan, 1963). De fato, observou-se que os comportamentos exploratórios (de informação e prática), assim como a participação em atividades de pesquisa foram preditores da auto-eficácia profissional, sugerindo que a exploração contribui para a formação do senso de competência profissional e este, por sua vez, é que está mais diretamente relacionado ao nível de decisão de carreira. Note-se que, da forma como foi operacionalizada neste estudo, a participação em monitorias não se mostrou relacionada nem com a decisão e nem com a auto-eficácia profissional. É possível que as atividades de monitoria difiram muito em sua qualidade de um curso (ou mesmo disciplina) para outro e, em média, o impacto destas atividades para a formação de competências profissionais seja realmente pequeno. De qualquer forma, os resultados sugerem a importância dos aspectos práticos da formação como fator que permite aos jovens adquirirem competências específicas e assim poderem delinear com mais clareza o seu próprio perfil profissional, aspecto que é fundamental para a elaboração de planos profissionais (Gondim, 2002).

Por fim, a análise de regressão que buscou identificar possíveis preditores da percepção pessoal de oportunidades profissionais - que pode ser entendida também como o otimismo dos formandos quanto ao seu estabelecimento na profissão - mostrou que a auto-eficácia profissional, a situação do mercado de trabalho e o apoio em relação ao projeto são fatores que contribuem significativamente para a formação de expectativas positivas quanto ao futuro profissional. Surpreendentemente, a participação em bolsas de pesquisa teve um peso negativo nesta análise, indicando que um maior tempo de participação está associado a expectativas menos otimistas. Talvez as atividades de pesquisa, embora promovam o desenvolvimento da auto-eficácia e qualifiquem o currículo pessoal, acabem afastando o estudante da realidade do mercado de trabalho (o tempo dedicado à pesquisa não pode ser dedicado a outras atividades de formação), o que resulta em uma avaliação pessoal mais pessimista das suas possibilidades de conseguir uma colocação profissional. Por outro lado, merece destaque o fato da auto-eficácia profissional estar relacionada a este otimismo quanto ao estabelecimento na carreira. Esse resultado nos mostra a importância de oferecer uma formação profissional que de fato promova o desenvolvimento da auto-eficácia dos estudantes, caso contrário o sentimento de falta de competência poderá gerar expectativas negativas quanto à possibilidade de obter um espaço no mercado de trabalho. Estas expectativas negativas, por sua vez, podem vir a dificultar a elaboração de metas profissionais. Por fim, a ausência de metas pode fazer com que os indivíduos não consigam executar nenhum plano efetivo de ação em relação à carreira, devido à falta de critérios para orientar e julgar a eficácia dos seus esforços, realimentando as expectativas negativas e gerando um ciclo de desmotivação e indecisão profissional.

Enfim, seria importante que a formação universitária contemplasse mais o aspecto da prática profissional e também instrumentalizasse o estudante para a transição para o mercado de trabalho, levando-o a refletir e responsabilizar-se sobre a sua trajetória dentro da universidade e sobre sua própria profissão. Deve-se observar que, mais do que a situação objetiva do mercado de trabalho, foi a maneira como os formandos perceberam o mercado a variável que mais explicou o seu nível de decisão de carreira, juntamente com 
as variáveis auto-eficácia profissional e clareza de autoconceito - o que indica a importância dos aspectos pessoais no desenvolvimento do projeto profissional (algo já apontado em outros estudos, por exemplo, Callegari, 2001).

Uma variável que merece ser investigada de modo mais específico em futuros estudos sobre o tema é o sexo. Nesta pesquisa o sexo foi incluído apenas para controlar a variabilidade relacionada ao gênero que pudesse estar presente nas demais variáveis preditoras. Embora em nenhuma das análises o sexo tenha emergido como um preditor das variáveis dependentes, não se pode concluir que seu papel seja irrelevante. De fato, sabe-se que as diferenças culturais no modo como homens e mulheres são socializados afetam o desenvolvimento vocacional e, possivelmente, o modo como formandos do ensino superior se preparam para o ingresso no mundo profissional. Assim, são necessários novos estudos que investiguem separadamente amostras de homens e mulheres, controlando a variável curso ou profissão. Na pesquisa aqui relatada, a amostra obtida foi proveniente de diversos cursos com proporções desiguais de homens e mulheres. Isso inviabilizou a realização de análises por sexo, uma vez que os possíveis efeitos de gênero se confundiriam com as especificidades dos cursos, impossibilitando uma interpretação acurada.

Duas ressalvas metodológicas, ainda, precisam ser feitas neste estudo. Em primeiro lugar, os participantes foram todos voluntários, o que pode ter introduzido algum viés nos resultados uma vez que formandos menos decididos podem não ter se sentido motivados a participar da pesquisa (é possível que os formandos indecisos apresentem comportamentos evitativos frente a situações que os confrontem com a necessidade de pensar sobre o futuro profissional, em virtude da ansiedade que tal confrontação pode gerar). Em segundo lugar, não foi possível obter uma avaliação realmente objetiva da situação do mercado de trabalho das diversas profissões, tendo-se tomado a média das representações individuais sobre o mercado de trabalho como um indicador da situação mais ou menos favorável do mercado. Por isso, os resultados aqui apresentados precisam ser considerados com cautela, e futuras pesquisas que superem essas limitações metodológicas fazem-se necessárias para que se possa confirmar (ou não) os achados deste estudo.

\section{Referências}

Albert, K. A. \& Luzzo, D. A. (1999). The role of perceived barriers in career development: A social cognitive perspective. Journal of Counseling and Development, 77, 431-436.

Bandura, A. (2001). Social Cognitive theory: An agentic perspective. Annual Review of Psychology, 52, 1-26.

Betz, N. E. (1994). Self-concept theory in career development and counseling. Career Development Quarterly, 43, 32-41.

Blustein, D. L. (1997). A context-rich perspective of career exploration across the life roles. Career Development Quarterly, 45, 260-274.

Blustein, D. L., Prezioso, M. S. \& Schultheiss, D. E. (1995). Attachment theory and career development: Current status and future directions. The Counseling Psychologist, 23, 416-432.

Callegari, M. M. (2001). A inserção profissional de egressos universitários. Dissertação de Mestrado, Pontifícia Universidade Católica do Rio Grande do Sul, Porto Alegre.
Campbell, J. D., Trapnell, P. D., Heine, S. J., Katz, I. M., Lavalle, L. F. \& Lehman, D. R. (1996). Self-concept clarity: Measurement, personality correlates, and cultural boundaries. Journal of Personality and Social Psychology, 70, 141-156.

Feldman, D. C. (2003). The antecedents and consequences of early career indecision. Human Resources Management Review, 13, 499-531.

Frischenbrüder, S. L. (1999). O desenvolvimento vocacional na adolescência: Autoconceito e comportamento exploratório. Dissertação de Mestrado, Pontifícia Universidade Católica do Rio Grande do Sul, Porto Alegre.

Gianakos, I. (1999). Patterns of career choice and career decisionmaking self-efficacy. Journal of Vocational Behavior, 54, 244-258.

Gondim, S. M. G. (2002). Perfil profissional e mercado de trabalho: Relação com a formação acadêmica pela perspectiva de estudantes universitários. Estudos de Psicologia, 7, 299309.

Graham, C. \& McKenzie, A. (1995). Delivering the promise: The transition from higher education to work. Education and Training, 37(1), 4-11.

Greenhaus, J. H., Callanan, G. A. \& Kaplan, E. (1994). The role of goal setting in career management. The International Journal of Career Management, 7(5), 3-12.

Jordaan, J. P. (1963). Exploratory behavior: The formation of self and occupational concepts. Em D. E. Super, R. Starishevsky, N. Matlin \& J. P. Jordaan (Orgs.), Career development: Selfconcept theory (pp. 42-78). New York: College Entrance Examination Board - Columbia Universtiy.

Kräcke, B. (1997). Parental behaviors and adolescents' career exploration. Career Development Quarterly, 45, 341-350.

Lent, R. W., Brown, S. D. \& Hackett, G. (1996). Career development from a social cognitive perspective. Em D. Brown, L. Brooks $\&$ cols. (Orgs.), Career choice and development. ( $3^{\mathrm{a}} \mathrm{ed}$.) (pp. 373-421). San Francisco: Jossey-Bass.

Lent, R. W., Brown, S. D. \& Hackett, G. (2000). Contextual supports and barriers to career choice: A social cognitive analysis. Journal of Counseling Psychology, 47, 36-49.

Mook, D. G. (1983). In defense of external invalidity. American Psychologist, 38, 379-387.

Neiva, K. M. C. (1995). Le comportment des étudiants brésiliens en fin d'études universitaires selon leurs débouchés professionnels: Une application du modèle Lisrel. Revue Européenne de Psychologie Appliquée, 45(2), 103-108.

Neiva, K. M. C. (1996). Fim dos estudos universitários: Efeitos das dificuldades do mercado de trabalho na representação do futuro profissional e no estabelecimento de projetos pós-universitários dos estudantes. Psicologia USP, 7(1/2), 203-224.

Osipow, S. H., Carney, C.G. \& Barak, A. (1976). A scale of Educational-Vocational Undecidedness: A Typological Approach. Journal of Vocational Behavior, 9, 233-243.

Perrone, L. \& Vickers, M. H. (2003). Life after graduation as a "very uncomfortable world": An australian case study. Education and Training, 45(2/3), 69-78.

Pinquart, M., Juang, L. P. \& Silbereisen, R. K. (2003). Self-efficacy and successful school-to-work transition. Journal of Vocational Behavior, 63, 329-346.

Spokane, A. R. (1996). Holland's theory. Em D. Brown, L. Brooks \& cols. (Orgs.), Career choice and development (pp. 33-74). San Francisco: Jossey-Bass Publishers. 
Stanovich, K. E. (2004). How to think straight about psychology. New York: Allyn and Bacon, Pearson Education, Inc.

Stumpf, S. A., Colarelli, S. M. \& Hartman, K. (1983). Development of the Career Exploration Survey (CES). Journal of Vocational Behavior, 23, 191-226.

Super, D. E. (1983). Assesment in career guidance: Toward truly developmetal counseling. Personnel and Guidance Journal, $61,555-562$.

Super, D. E., Savickas, M. L. \& Super, C. M. (1996). The lifespan, life-space approach to careers. Em D. Brown, L. Brooks $\&$ cols. (Orgs.), Career choice and development. ( $3^{\mathrm{a}}$ ed., p. 121-178). San Francisco: Jossey-Bass.

Swanson, J. L. \& Tokar, D. M. (1991). College students' perceptions of barriers to career development. Journal of Vocational Behavior, 38, 92-106.
Tokar, D. M., Withrow, J. R., Hall, R. \& Moradi, B. (2003). Psychological separation, attachment security, vocational self-concept crystalization, and career indecision: A structural equation analysis. Journal of Counseling Psychology, 50, 3-19.

Tabachnik, B. G. \& Fidell, L. S. (2001). Using multivariate statistics ( $4^{\mathrm{a}}$ ed.). Boston: Allyn and Bacon.

Recebido em 15.04.2005

Primeira decisão editorial em 10.08.2005

Versão final em 03.12.2005

Aceito em 12.12.2005 